\title{
THE
}

1997

\section{Evidence for Cholinergic Inhibitory and Serotonergic Excitatory Neuromuscular Transmission in the Heart of the Bivalve Mercenaria mercenaria}

Kiyoaki Kuwasawa

Robert A. Hill

University of Rhode Island

Follow this and additional works at: https://digitalcommons.uri.edu/bio_facpubs

Terms of Use

All rights reserved under copyright.

\section{Citation/Publisher Attribution}

Kuwasawa, K. \& Hill, R. B. (1997). Evidence for Cholinergic Inhibitory and Serotonergic Excitatory Neuromuscular Transmission in the Heart of the Bivalve Mercenaria mercenaria. Journal of Experimental Biology, 200, 2123-2135. Retrieved from http://jeb.biologists.org/content/200/15/2123.

Available at: http://jeb.biologists.org/content/200/15/2123 


\title{
EVIDENCE FOR CHOLINERGIC INHIBITORY AND SEROTONERGIC EXCITATORY NEUROMUSCULAR TRANSMISSION IN THE HEART OF THE BIVALVE MERCENARIA MERCENARIA
}

\author{
KIYOAKI KUWASAWA ${ }^{1}$ AND ROBERT B. HILL ${ }^{2, *}$ \\ ${ }^{1}$ Department of Biology, Tokyo Metropolitan University, Hachioji-shi, Tokyo 192-03, Japan and \\ ${ }^{2}$ Department of Biological Sciences, University of Rhode Island, Kingston, RI 02881, USA
}

Accepted 23 May 1997

\section{Summary}

The heart of Mercenaria mercenaria is innervated bilaterally at the atria. A pair of cardiac nerves arise as a branch of the cerebro-visceral connective and run to the posterior end of the junction between each atrium and its efferent branchial vessel. Innervation evidently spreads over the heart, since both inhibitory and excitatory junctional potentials (IJPs and EJPs) can be recorded from the atria, the atrio-ventricular ( $\mathrm{AV}$ ) valve or the ventricle.

The cardiac nerves contain inhibitory and excitatory axons. Neural stimulation can cause increases in the frequency or amplitude of beating, depending on the strength and frequency of stimulation. Electrical stimulation of the nerves to the incurrent and excurrent siphons causes bradycardia or tachycardia even after cutting the cerebro-visceral connective at a site anterior to the origin of the cardiac nerves. This may indicate a reflex pathway involving neurons whose cell bodies are located in the visceral ganglion.

Neural depression of myocardial action potentials is mediated by discrete IJPs, which follow nerve stimuli oneto-one. IJPs can be recorded from the atria, the $\mathrm{AV}$ valve or the ventricle. A long-lasting hyperpolarization follows cessation of excitatory stimulation of the cardiac nerve.

IJPs may be produced by cholinergic nerves and are mediated primarily by $\mathrm{Cl}^{-}$. They are blocked by Mytolon and by $d$-tubocurarine (dTC), but not by methylxylocholine. In low-[Cl-] solution, IJPs are inverted into depolarizing junctional potentials, which are blocked by Mytolon and dTC.

Neurally induced tachycardia is mediated by discrete EJPs, which also follow stimuli applied to the cardiac nerve in a one-to-one manner. EJPs can be recorded from the atria, the $A V$ valve and the ventricle.

The myocardium and the AV valve were excited by application of serotonin. EJPs recorded from these sites were reduced in amplitude by methysergide (1-methyl- $d$ lysergic acid butanolamide), suggesting that the EJPs may be serotonergic.

Just after entering the heart, at the posterior end of the junction with the efferent branchial vessel, the cardiac nerves contain thick processes which show serotonin-like immunoreactivity. These processes spread along the ramifications of the nerves, which extend to the atrium, the $A V$ valve, the ventricle and even into the wall of the aorta.

This study provides direct electrophysiological evidence for serotonergic EJPs and cholinergic IJPs, plus immunocytochemical evidence for neural processes containing serotonin, in the myocardium.

Key words: mollusc, heart, unitary postjunctional potential, Mercenaria mercenaria.

\section{Introduction}

Postjunctional potentials, resulting from stimulation of cardioexcitatory nerves, provide direct evidence of neuromuscular transmission to myocardial cells. Microelectrode recording from myocardial cells of gastropods and cephalopods has enabled us to demonstrate the existence of discrete individual EJPs, which show one-to-one correspondence with stimuli applied to cardiac nerves (reviewed by Hill and Kuwasawa, 1990). The chemical neurotransmitter for EJPs elicited by molluscan cardioexcitatory nerves may show wide physiological variation across the molluscan phylum, but serotonin (5-HT) has long been postulated as the neurotransmitter in many cases. Monoamines have been localized in varicosities on cardiac nerves in the central heart of Sepia officinalis (Kling, 1986). Recently, immunocytochemical methods have been used to identify serotonin in cardiac nerves of the gastropods Aplysia californica (Goldstein et al. 1984; Ono et al. 1992) and Pleurobranchaea novaezealandiae (Kuwasawa et al. 1990). In

*Author for correspondence (e-mail: gsy101@uiracc.uri.edu). 
bivalve molluscs, there have been no previous studies providing direct electrophysiological evidence for neural control of the heart by EJPs, nor have serotonergic neural processes been demonstrated, although the hearts of bivalves have been used extensively for bioassays and for physiological and pharmacological experiments. Although Liebeswar et al. (1975) showed that a specific serotonergic blocker (cinanserin) antagonized excitatory neuromuscular transmission in the heart of A. californica, no specific serotonergic blocking agent has yet been tested against neurally induced excitation of a bivalve heart.

Bivalve hearts (Welsh and Taub, 1948, 1953; Greenberg, 1965; Irisawa, 1978) and gastropod hearts (Hill, 1974b; Kuwasawa, 1979; Hill and Kuwasawa, 1990) may be excited or inhibited by acetylcholine (ACh). These responses may resemble the responses of molluscan neurons to $\mathrm{ACh}$, classified by Gerschenfeld (1973). Common responses of neurons were as follows: D-responses (or excitatory postsynaptic potentials, EPSPs) blocked by dTC, hexamethonium and strychnine; rapid H-responses (or fast inhibitory postsynaptic potentials, IPSPs) which reversed at $-60 \mathrm{mV}$ and were blocked by dTC and strychnine; and slow $\mathrm{H}$-responses (or slow IPSPs), which reversed at $-80 \mathrm{mV}$ and were blocked by tetraethylammonium and methylxylocholine. The ionic mechanisms of these neuronal responses appeared to involve changes in permeability mainly to $\mathrm{Na}^{+}$(D-responses), $\mathrm{K}^{+}$(slow $\mathrm{H}$-responses) and $\mathrm{Cl}^{-}$(fast $\mathrm{H}$-responses). However, there is a rather wide range of physiological variation among molluscan neuronal membranes, and it is not easy to fit the gastropod neuronal ACh receptors into the vertebrate classification of nicotinic and muscarinic receptors.

Elliott (1980) showed that ACh responses in cardiac muscle cells of M. mercenaria, Mytilus edulis and Crassostrea virginica can be compared with responses in ganglion cells of A. californica (Tauc and Gerschenfeld, 1962; Kehoe, 1972a,b; Gerschenfeld, 1973). The slow H-response of the $M$. mercenaria ventricle appears to be pharmacologically identified with the 'slow, potassium-mediated hyperpolarizing cholinergic responses' of A. californica neurons (Elliott, 1979). The ventricle of Mytilus edulis shows a D-response to ACh (Elliott, 1980; Shigeto, 1970). Elliott used ionophoretic application of ACh and found the D-response to be primarily $\mathrm{Na}^{+}$-dependent, resembling the $\mathrm{Na}^{+}$-dependent $\mathrm{ACh}$ response of A. californica neurons, which is abolished by hexamethonium. The ventricle of $C$. virginica shows a biphasic rapid D-response and slow H-response to ACh (Elliott, 1980). The D-phase, which is blocked by dTC, is due to an increase in $\mathrm{Cl}^{-}$permeability, resembling the $\mathrm{Cl}^{-}$-mediated $\mathrm{ACh}$ responses of A. californica neurons, while the $\mathrm{H}$-phase, which is antagonized by methylxylocholine, is due to an increase in $\mathrm{K}^{+}$permeability. The rapid $\mathrm{Na}^{+}$-mediated D-response, the rapid $\mathrm{Cl}^{-}$-mediated $\mathrm{D}$-response and the slow $\mathrm{K}^{+}$-mediated $\mathrm{H}$ response of bivalve myocardial cells correspond to the three types of ACh responses of A. californica ganglion cells (Elliott, 1979, 1980). The $\mathrm{K}^{+}$-mediated H-response may be responsible for neurally induced cardiac inhibition (Elliott, 1980). In gastropod and cephalopod species, we have shown that neural cardiac excitation and inhibition are mediated by discrete EJPs and IJPs and that, in the gastropod heart, IJPs are AChmediated $\mathrm{Cl}^{-}$currents antagonized by dTC (Kuwasawa et al. 1987; Hill and Kuwasawa, 1990). Cardiac bioassay studies on isolated hearts of a variety of bivalves have shown myocardial excitation or inhibition by serotonin (Greenberg, 1960, 1965; Irisawa et al. 1973; Painter and Greenberg, 1982). Loveland (1963b) proposed that serotonin was probably a mediator for neurally induced excitation of the heart of $M$. mercenaria. Hill and Kuwasawa (1990) showed that serotonin depolarized myocardial cells in the AV valve of M. mercenaria. Devlin $(1993 a, b)$ has shown that the entire ventricle of the same species was activated by serotonin. Thus, serotonin has been identified as a cardio-excitatory neurohumor or neurotransmitter of cardioexcitatory nerves. However, there is still a need for direct electrophysiological evidence for excitatory and inhibitory neuromuscular transmission in the heart of bivalve molluscs. It is also necessary to determine the pharmacological features of the mechanisms of neurally mediated cardiac responses.

In this study, we provide direct electrophysiological evidence for serotonergic EJPs and cholinergic IJPs, and immunocytochemical evidence for the presence of serotoninlike neural processes in the myocardium of a member of the Bivalvia.

\section{Materials and methods}

Experiments were performed at the University of Rhode Island and at Tokyo Metropolitan University, using Mercenaria mercenaria L. obtained from commercial suppliers in the USA. Animals ranged in shell length from 9.5 to $12.5 \mathrm{~cm}$ and in mass (with shell) from 215 to $635 \mathrm{~g}$.

\section{Preparations}

Cardiac responses to stimulation of nerves arising from the visceral ganglion and the cerebro-visceral connective were recorded from preparations which contained the heart and the visceral ganglion. To obtain the preparation, the umbo of the animal lying on its side was gently crushed with a wooden hammer, and the valves were removed by peeling away the bases of the anterior and posterior adductor muscles. We exposed the nerves arising from the visceral ganglion, including nerves to the incurrent and excurrent siphons and to the cerebro-visceral connective. The nerves to the siphons were cut at a site a few centimeters from the ganglion. One of the paired connectives, between the visceral and cerebral ganglia, was cut between the visceral ganglion and the nerve to the heart. The other connective was cut at a site beyond the root of the nerve to the heart.

The mass which contained the heart, visceral ganglion and the almost entire paired gill was incised and pinned to a pair of platforms in the experimental bath $(10 \mathrm{~cm} \times 10 \mathrm{~cm} \times 10 \mathrm{~cm})$ dorsal side up, inserting the mass into the groove between the platforms. A cannula was inserted into one of the paired 
efferent branchial vessels to perfuse the heart with filtered sea water (SW). The preparations were perfused with SW running from a reservoir tank through the cannula. A longitudinal incision was made in the median region above the ventricle to expose the heart and the anterior and posterior aortae. These arteries were cut to make a smooth run of perfusate inside the heart. The atrium on the side contralateral to the side with the cannula inserted in the branchial vessel was severed from the gill at the junction between the atrium and ventricle. The cut end of the ventricle was ligatured to a mechanotransducer with a thin plastic thread.

After the shell had been removed, the heart was isolated for use in recording intracellular myocardial potentials. The isolated ventricle was cut longitudinally and the atrium transversely. One of the pairs of AV valves was pinned out as a flap along the midline. The preparation was pinned flat in a Sylgard-lined perfused experimental bath. In most cases, major parts of the atrium and the ventricle were removed from the preparation, leaving myocardial trabeculae of the atrium and ventricle and pieces of the myocardial sheets of the $\mathrm{AV}$ valve at the junction of the atrium, the AV valve and the ventricle. This was done in order to avoid strong contractions which make long-lasting intracellular recording with microelectrodes difficult. In preparations for recording intracellular junctional potentials, the intra-atrial cardiac nerve was isolated over as long a length as possible from myocardial trabeculae. It was then cut to make the cut distal stump free and long enough to be introduced into a stimulating glass suction electrode.

\section{Electrophysiology}

Approximately 50 specimens were used, of which seven were used for mechanograms. Contractions of the heart were recorded with a strain gauge transducer (Nihon Kohden) from a ligature tied to the cut end of the ventricle.

Twenty-seven specimens were used for electrophysiological recording. Recordings of EJPs and IJPs were made using conventional glass microelectrodes, consisting of micropipettes filled with $3 \mathrm{moll}^{-1} \mathrm{KCl}$, tip resistance 20-30 M $\Omega$. The arrangement of the reference electrode depended on the perfusion medium used. When the specimens were perfused with normal artificial sea water (ASW), a $\mathrm{Ag}-\mathrm{AgCl}$ reference electrode was placed directly in the bath. When experiments recording IJPs in $\mathrm{Cl}^{-}$-deficient ASW were performed, a $\mathrm{Ag}-\mathrm{AgCl}$ reference electrode communicated with the bath via a $3 \mathrm{moll}^{-1} \mathrm{KCl}$ reservoir, and one end of a $3 \mathrm{moll}^{-1}$ $\mathrm{KCl}$ agar bridge was positioned at the site in the bath where the perfusate was removed by suction with an aspirator. Membrane potentials were displayed in real time using a cathode ray oscilloscope (CRO) (Nicolet or Nihon Kohden) and a pen-writing oscillograph (Nihon Kohden). They were recorded with a DAT recorder (TEAC) and displayed later with these instruments. A cardiac nerve was cut just where it entered an atrium and the distal stump was introduced into a glass capillary suction electrode. Electric pulses (1-3 ms in duration) were applied to the stump while the cardiac mechanogram was recorded.
Preparations were perfused by gravity feed and suction removal. A standard artificial sea water (ASW) for molluscs was used (Kuwasawa and Yazawa, 1981). Low- $\left[\mathrm{Cl}^{-}\right] \mathrm{ASW}$ was prepared by substituting sodium methanesulfonate for $\mathrm{NaCl}$ in normal ASW (in mmoll ${ }^{-1}: \mathrm{NaCl}, 458 ; \mathrm{KCl}, 10.5 ; \mathrm{CaCl}_{2}, 10.5$; $\mathrm{MgCl}_{2}, 28 ; \mathrm{MgSO}_{4}, 22 ;$ Hepes, $5 ; \mathrm{pH} 7.8$ ). The $\mathrm{Cl}^{-}$-deficient ASW contained $458 \mathrm{mmoll}^{-1}$ sodium methanesulfonate, $3 \mathrm{mmoll}^{-1} \mathrm{NaOH}$ (used for adjustment of $\mathrm{pH}$ to 7.8 ) and the same concentrations of the other salts as in normal ASW.

The following chemicals were used: $d$-tubocurarine chloride (Sigma), acetylcholine chloride (Sigma), serotonin (5hydroxytryptamine creatinine sulfate complex), benzoquinonium chloride (also called Mytolon) (a gift from the Sterling-Winthrop Research Institute), methylxylocholine chloride ( $\beta$-methyl TM 10) (a gift from Smith, Kline and French Laboratories) and methysergide [1-methyl- $d$-lysergic acid-(+)-1-hydroxy-2-butylamide (UML 491)] (a gift from Sandoz).

\section{Immunocytochemistry}

Whole-mount preparations of the heart were used for immunocytochemical localization of serotonin. Isolated opened hearts were pinned to a Sylgard-lined dish. A peroxidase-antiperoxidase method was followed, similar to that described elsewhere (Kurokawa et al. 1989; Kuwasawa et al. 1992). Variations in fixative procedures were applied to the preparations according to Berod et al. $(1981,1982)$.

Specimens were first fixed by immersion in a mixture of paraformaldehyde $(4 \%)$ and 0.1 mol l$^{-1}$ sodium acetate buffer at $\mathrm{pH} 6.5$, containing $30 \%$ sucrose $(\mathrm{w} / \mathrm{v})$, and then the fixative was replaced with the second fixative (Kurokawa et al. 1989) at $\mathrm{pH} 9.0$, adjusted with $0.1 \mathrm{moll}^{-1}$ sodium borate buffer. Before immunotreatment of specimens, some fixed specimens were incubated in SW containing $0.3 \%$ collagenase (Sigma, Type I) for $2 \mathrm{~h}$ at $20-25^{\circ} \mathrm{C}$ and then washed in phosphate-buffered saline. Treatment of the specimens with collagenase was varied to obtain the best result. The rabbit anti-serotonin antiserum (primary antiserum) (Incstar) was used at a dilution of 1:1000 to $1: 2000$, the goat anti-rabbit $\operatorname{IgG}$ (secondary antiserum) at a dilution of 1:200, and the rabbit peroxidase-antiperoxidase complex (Sigma) at a dilution of 1:200. After reacting with $0.3 \mathrm{mg} \mathrm{m}^{-1}$ diaminobenzidine tetrahydrochloride containing $0.006 \% \mathrm{H}_{2} \mathrm{O}_{2}$, preparations were dehydrated in an ethanol series. To make whole-mount preparations, specimens were cleared in methyl salicylate and mounted whole on glass slides. The primary antiserum absorbed with serotonin $\left(10^{-4} \mathrm{moll}^{-1}\right)$ was used as a control serum and no specific labelling was seen. In addition, specimens incubated only with the secondary antiserum showed no specific labelling greater than the background. The preparations were observed under a microscope and photographed.

\section{Results}

Central origin of excitatory and inhibitory cardiac nerves

We can confirm previous studies of the neural anatomy of 

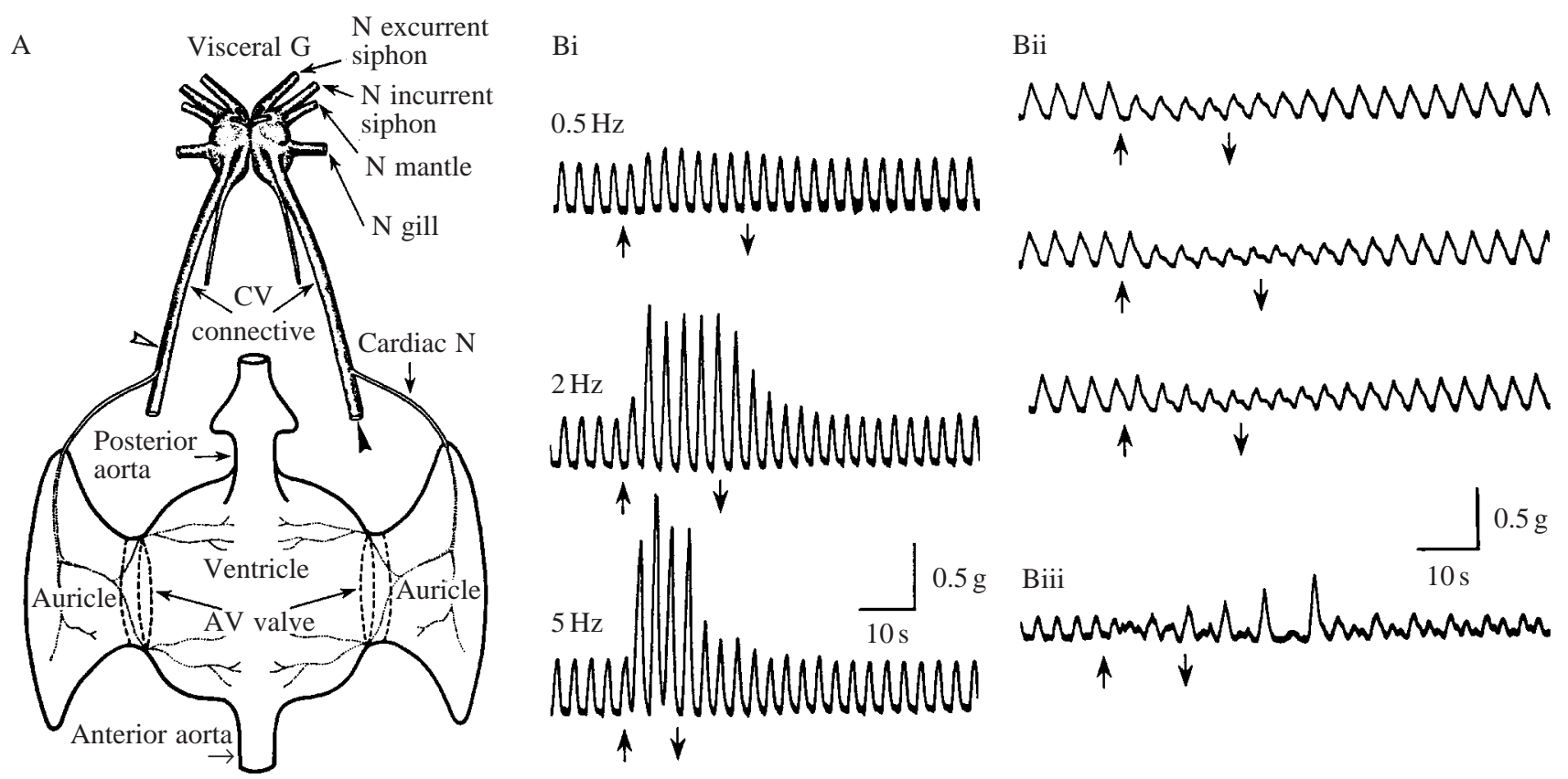

Fig. 1. (A) A schematic diagram of the visceral ganglion and the gross anatomy of cardiac innervation in Mercenaria mercenaria. (B) Cardiomechanograms from the ventricle, in a preparation like that shown in A, recording the responses to stimuli applied to nerves arising from the visceral ganglion. (Bi) The left cerebro-visceral connective was cut between the visceral ganglion and the cardiac nerve (open arrowhead in A), and the distal end was stimulated at $0.5-5 \mathrm{~Hz}$. (Bii) The right cerebro-visceral connective was cut between the visceral ganglion and the cerebral ganglion (filled arrowhead in A), and stimuli were applied at $5 \mathrm{~Hz}$ to the nerves to the left incurrent and excurrent siphons (Bii, top and middle traces) and mantle (Bii, bottom trace) and to the right cerebro-visceral connective (Biii). G, ganglion; N, nerve; CV, cerebro-visceral; $\mathrm{AV}$, atrio-ventricular.

M. mercenaria which showed that the heart receives a pair of cardiac nerves that run over the reno-pericardial ducts after branching from the cerebro-visceral connectives (Loveland, 1963a). Twelve specimens were used for anatomical studies.

The nerves enter the heart at the posterior end of the junction between the atrium and the gill on both sides just posterior to the reno-pericardial ducts. The cardiac nerve usually appears as one bundle just after the nerve enters the auricle and then arborizes throughout the atrium, AV valve, ventricle and aortic bulb (Fig. 1A).

Loveland (1963b) reported that excitation of the heart in $M$. mercenaria was seen only after the inhibitory mechanism was blocked by a drug. However, we found that, in a preparation in which the cardiac nerve on one side was intact, the heart showed excitation and inhibition in response to stimulation of the nerves arising from the visceral ganglion or the cerebrovisceral connective. Heartbeats were enhanced in amplitude by stimulation of the cerebro-visceral connective (Fig. 1Bi), depressed in amplitude by approximately $50 \%$ when nerves to the contralateral incurrent and excurrent siphons and mantle were stimulated (Fig. 1Bii), and showed concomitant depression and enhancement on stimulation of the ipsilateral cerebro-visceral connective (Fig. 1Biii). To assess the ganglionic origin of neurons sending cardiac motor axons to the heart, the connective was severed from both the visceral and cerebral ganglia and stimulated at the two cut ends; that is, between the cardiac nerve and the visceral ganglion, and between the cardiac nerve and the cerebral ganglion. Excitatory and inhibitory effects or combined effects were only observed when the cut cerebro-visceral connective was stimulated at the stump on the side of the visceral ganglion. These results may indicate that the excitatory and inhibitory effects were brought about by axons originating in the visceral ganglion.

\section{Serotonin-like immunoreactive neural processes}

We observed clear serotonin-like immunoreactive neural processes in the whole heart in four specimens. Examples of the processes in the atrium, in the AV valve and in the ventricle are shown in Fig. 2. The Y-shaped trunk of the immunoreactive processes shown in Fig. 2Ai is the cardiac nerve just after entering the atrium. Thin fibers with immunoreactive varicosities run or spiral densely around muscle trabeculae in the atrium (Fig. 2Aii), as shown in the auricle of the heterodont bivalves by Ono et al. (1992). The cardiac nerve continues on to the AV valve, giving off branching fibers (Fig. 2Bi). Anastomosing structures are seen in the valve (Fig. 2Bii) or at sites near it. The cardiac nerve extends to innervate the ventricle through the two junctions of the paired flaps of the $\mathrm{AV}$ valve with the ventricle (Fig. $2 \mathrm{Ci}$ ). A dense array of fine fibers runs along the ventricular trabeculae. These fibers, like those found in the other regions of the heart, have immunoreactive varicosities, which are characteristic structures at sites for release of neurotransmitters. 
Fig. 2. Serotonin-like immunoreactive neural processes that respond to rabbit anti-serotonin antibody in the atrium (A), the atrio-ventricular (AV) valve (B) and the ventricle (C). (Ai) A Yshaped thick process (arrow) at the point where the cardiac nerve enters the atrium, at the posterior end of the junction between the atrium and efferent branchial vessel. (Aii) The thick process arborizes on myocardial trabeculae. Immunoreactive varicosities (thin arrows) are seen on fine branches. Some of the fine fibers (thick arrow) spiral around the trabeculae. (Bi) A thick process (arrow) traverses the basal part of a flap of the AV valve to extend from the atrium to the ventricle and sends fine fibers onto the muscle sheet. (Bii) Immunoreactive anastomosing structures (arrows) are sometimes seen on the AV valve or around the junction of the atrium, AV valve and ventricle. (Ci) The thick process (arrow) enters the ventricle and sends fine processes along the trabeculae. (Cii) A thick ventricular trabeculum (arrow) is covered with as many fine processes as are found on the atrial trabeculae, but spiraling fibers are not seen. Scale bars, $100 \mu \mathrm{m}$.

\section{$\mathbf{A i}$}
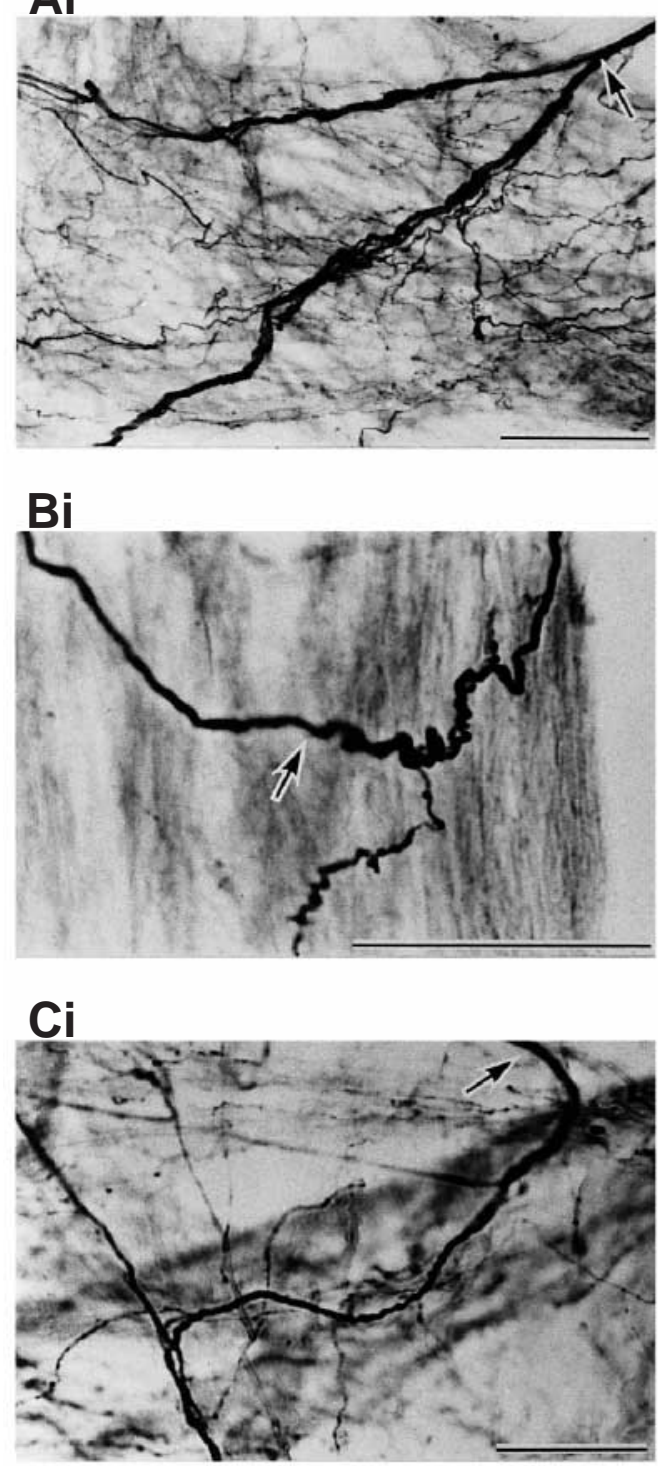

Aii

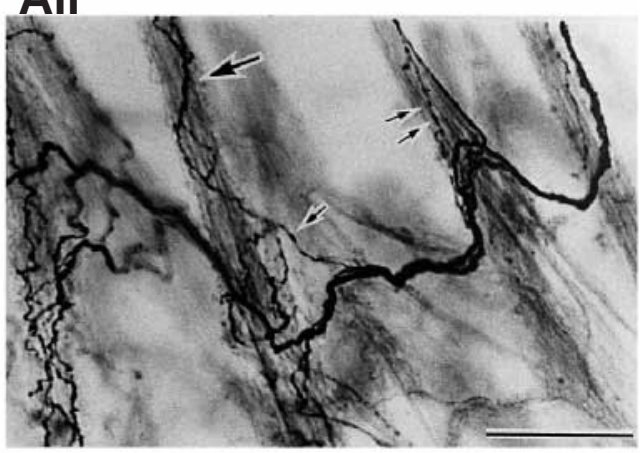

$\mathrm{Bii}$

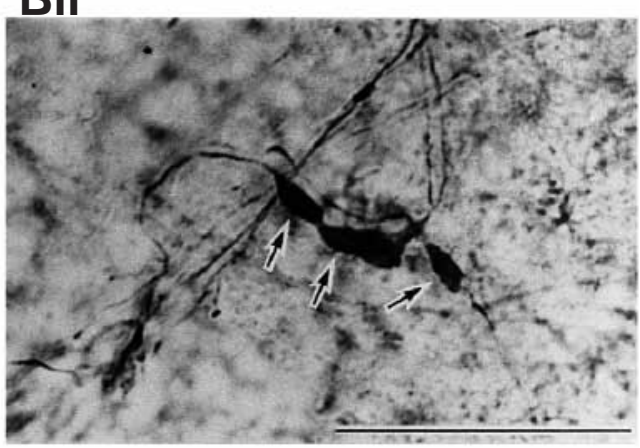

\section{Cii}

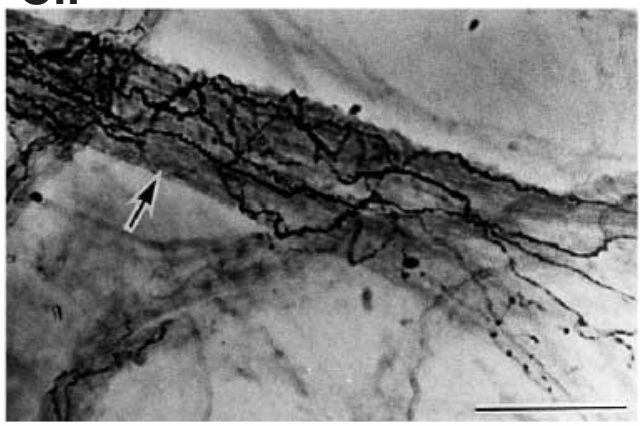

\section{Excitatory and inhibitory neuro-myocardial transmission}

Values for the resting potentials in myocardial cells of the atrium were $-54.1 \pm 3.9 \mathrm{mV}$ (mean \pm S.D., $N=6$ ), of the $\mathrm{AV}$ valve were $-50.7 \pm 4.8 \mathrm{mV}(N=88)$ and of the ventricle $-51.2 \pm 5.0(N=52)$. Cells with membrane potential below $35 \mathrm{mV}$ were discarded. Twenty-seven specimens were used for electrophysiological observations.

\section{Excitatory innervation}

Stimulation of the cardiac nerve of $M$. mercenaria elicited single EJPs in a one-to-one ratio in response to stimulus pulses in all sites of the heart tested including the atrium, AV valve (Fig. 3A) and ventricle. EJPs elicited by stimuli of more than $5 \mathrm{~Hz}$ showed summation. However, stimulation probably excites both excitatory and inhibitory axons, since a longlasting hyperpolarization followed the cessation of excitatory stimulation when the stimulus frequency was as high as $10 \mathrm{~Hz}$ (Fig. 3B). The excitatory effects of serotonin on another molluscan heart have been shown to be blocked by cinanserin (Liebeswar et al. 1975). However, there has been no direct evidence showing myocardial EJPs blocked by any serotonergic antagonist. In the present study, the amplitude of EJPs in the AV valve, induced by stimuli to the intra-atrial cardiac nerve, was reduced by a $10 \mathrm{~min}$ treatment with $10^{-6} \mathrm{moll}^{-1}$ methysergide (Fig. 4) and recovered during washing with ASW (data not shown).

\section{Inhibitory innervation}

The mediation of neural cardiac inhibition by individual IJPs has been demonstrated in opisthobranch (Kuwasawa, 1967; Kuwasawa et al. 1987) and prosobranch (Kuwasawa and Hill, 1973) gastropods and in the octopus (Hill and Kuwasawa, 1990). We have now succeeded in recording IJPs from the myocardium of a species in another major molluscan taxon, the Bivalvia, and have examined the pharmacological and ionic mechanisms of neuromuscular transmission. 
A

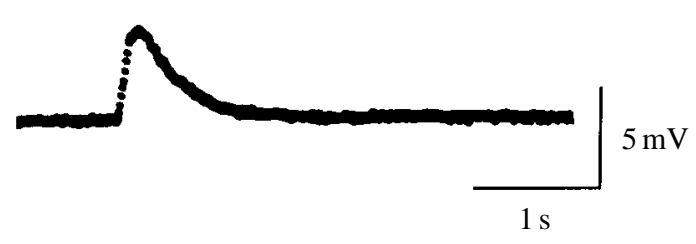

B

$0.5 \mathrm{~Hz}$

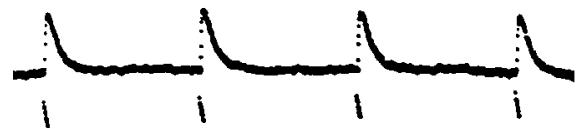

гн - Illummunu

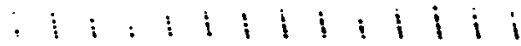

$5 \mathrm{~Hz}$

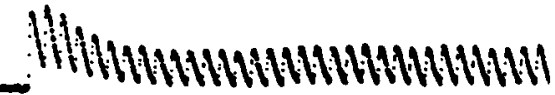

hillillibibliblillibib!

$10 \mathrm{~Hz}$

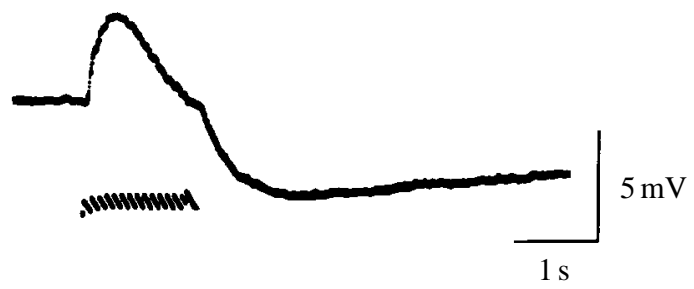

Fig. 3. (A) A single discrete excitatory junctional potential (EJP) in the atrio-ventricular (AV) valve. This was elicited by a stimulus to the intra-auricular distal cut end of the cardiac nerve in a glass suction electrode. (B) EJPs were induced in a ventricular myocardial cell by repetitive stimuli applied to the cardiac nerve at $0.5,2,5$ and $10 \mathrm{~Hz}$ (as labelled). In the last trace, the EJPs show summation, but a long period of hyperpolarization follows the cessation of stimulation. In each record, the lower trace identifies the point at which stimuli were applied.

A single discrete hyperpolarizing IJP, induced in the AV valve by stimulation of the cardiac nerve, is shown in Fig. 5A. IJPs summated progressively at stimulation rates from 1 to $5 \mathrm{~Hz}$, thus inducing maintained hyperpolarization which increased with the frequency of neural activation (Fig. 5B). IJPs induced by stimulation of the cardiac nerve in the ventricle at approximately $0.5 \mathrm{~Hz}$ effectively inhibited myocardial action potentials (Fig. 6). Regular trains of action potentials in the ventricle were also interrupted by a train of IJPs (Fig. 7), although the hyperpolarization of summated IJPs was followed by brief rebound-enhancement of action potentials (in the middle trace of Fig. 7).

Mytolon is known to block the inhibitory actions of ACh on the heart of bivalves (Welsh and Taub, 1953; Greenberg, 1965) and we found that the IJPs were almost completely blocked by
Control

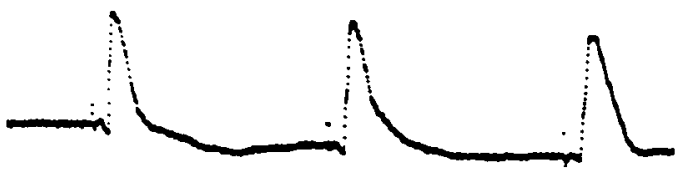

Methysergide

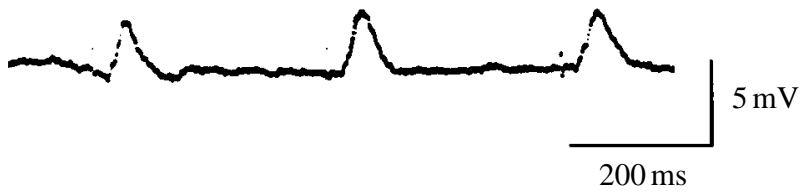

Fig. 4. Methysergide $\left(10^{-6} \mathrm{moll}^{-1}\right)$ reduced the amplitude of excitatory junctional potentials (EJPs) in the atrio-ventricular (AV) valve. The EJPs were elicited by stimuli applied to the intra-atrial distal cut end of the cardiac nerve.

A

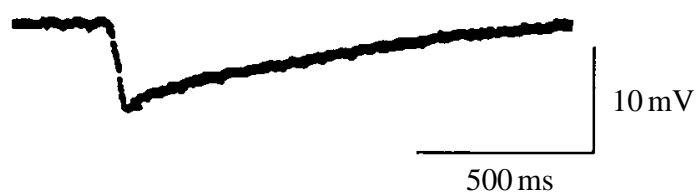

B

$1 \mathrm{~Hz}$

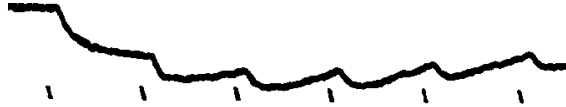

$2 \mathrm{~Hz}$
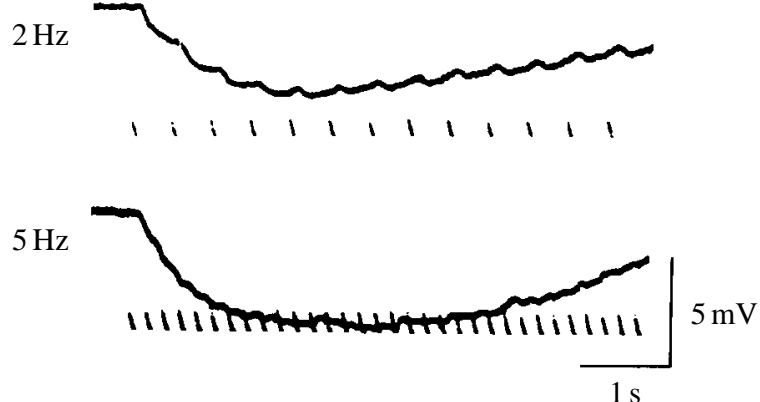

Fig. 5. (A) A stimulus applied to the intra-atrial distal cut end of the cardiac nerve evoked a single discrete hyperpolarizing inhibitory junctional potential (IJP) in a ventricular muscle cell. (B) IJPs in the atrio-ventricular (AV) valve were induced by stimuli applied to the intra-atrial cardiac nerve as indicated. These IJPs summated increasingly with frequency at 1,2 and $5 \mathrm{~Hz}$.

$3 \times 10^{-7}$ moll $^{-1}$ Mytolon (Fig. 8). $d$-Tubocurarine has been shown to block the depolarizing potential induced in $M$. mercenaria heart by ACh (Elliott, 1980), but our results show that hyperpolarizing IJPs were blocked by $d$-tubocurarine (Fig. 9). Single IJPs were almost completely blocked by the doses used and then recovered during a wash with ASW (Fig. 9A). 

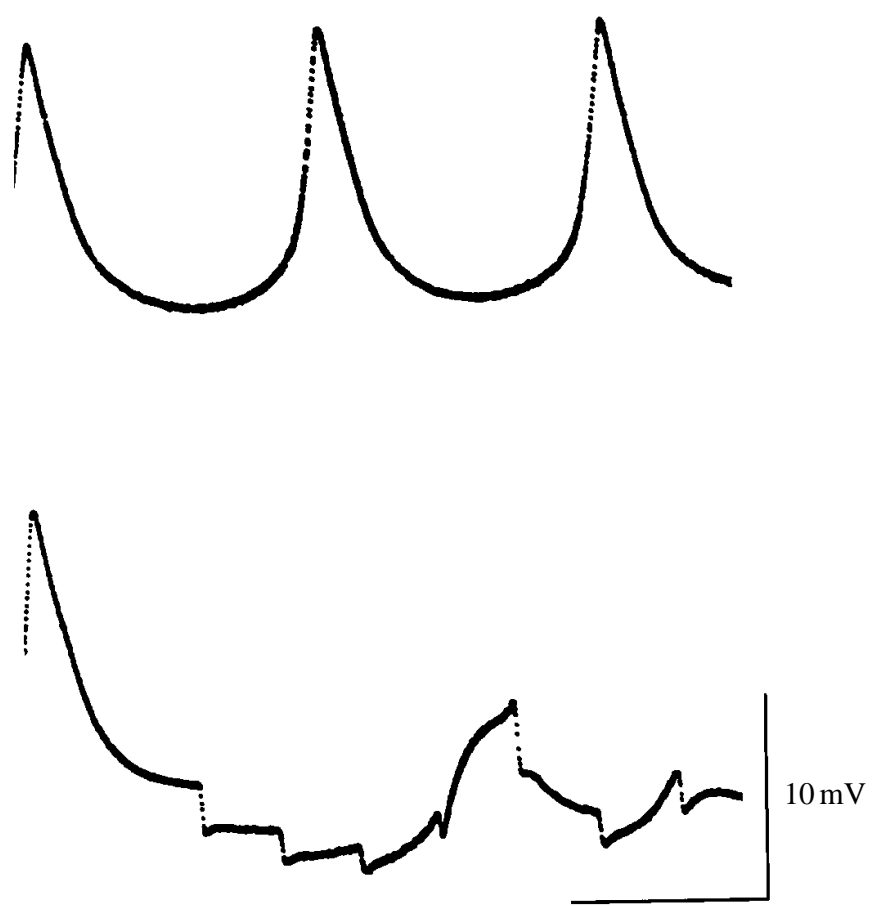

$5 \mathrm{~s}$

Fig. 6. Spontaneously arising cardiac action potentials of the ventricle (upper trace) were inhibited by a train of inhibitory junctional potentials (IJPs) evoked by stimulation of the intra-atrial cardiac nerve (lower trace).

Summated IJPs were also clearly antagonized by $10^{-4} \mathrm{moll}^{-1}$ dTC (Fig. 9B). The blocking effect also appeared as a depression of anodal break potentials, which were generated following the cessation of a train of stimuli in ASW. The IJPs and anodal break excitation recovered during washing with ASW. These results indicate that the IJPs are cholinergic. Similarly, it has been shown that, in the gastropod molluscs Dolabella auricularia and Pleurobranchaea novaezealandiae, IJPs in the heart are blocked by Mytolon and dTC (Kuwasawa and Yazawa, 1981; Kuwasawa et al. 1987).

\section{Ionic mechanisms of IJPs}

To examine their ionic mechanisms, IJPs were induced in preparations perfused with $\mathrm{Cl}^{-}$-deficient saline in which $\mathrm{NaCl}$ was replaced by sodium methanesulfonate. IJPs inverted to depolarizing potentials in the low- $\left[\mathrm{Cl}^{-}\right]$saline (Fig. 10). However, the resting membrane potential of valve muscle cells showed virtually no shift or shifted only a few millivolts to depolarized levels. The IJPs inverted into depolarizing potentials were still antagonized by low- $\left[\mathrm{Cl}^{-}\right]$perfusate containing dTC (Fig. 11). These results show that the IJPs are $\mathrm{Cl}^{-}$-mediated.

Methylxylocholine is an effective antagonist to the longlasting hyperpolarizing potentials induced by $\mathrm{ACh}$ in $M$. mercenaria heart (Elliott, 1980) and in a variety of molluscan neurons (Gerschenfeld, 1973). However, methylxylocholine did not exert noticeable effects on the normal and inverted IJPs

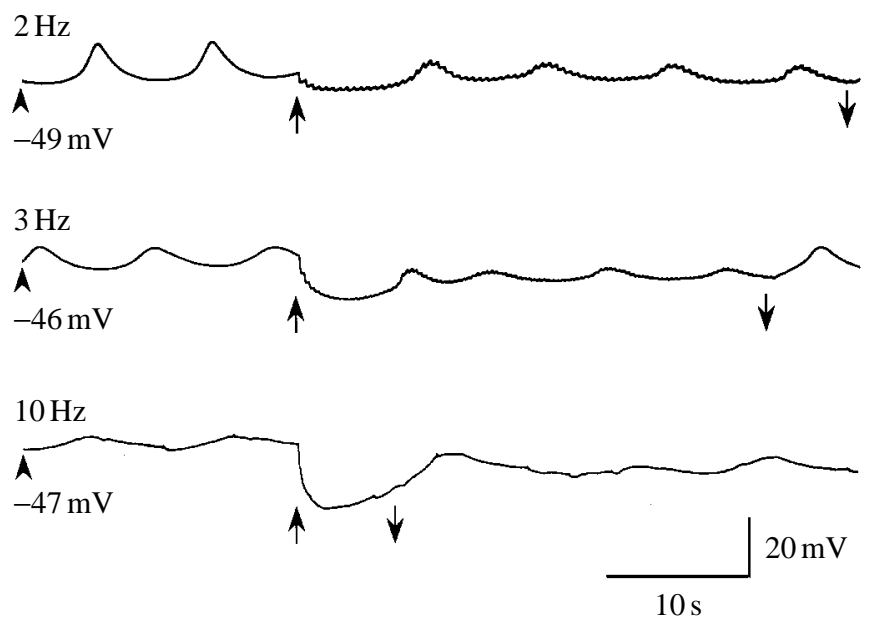

Fig. 7. Increasingly summated inhibitory junctional potentials (IJPs) of the ventricle induced by stimulation at $2 \mathrm{~Hz}$ (upper trace), $3 \mathrm{~Hz}$ (middle trace) and $10 \mathrm{~Hz}$ (bottom trace). Arrowheads indicate the period of stimulation. The cardiac cycle was increasingly disrupted as seen in the action potential of the ventricle.
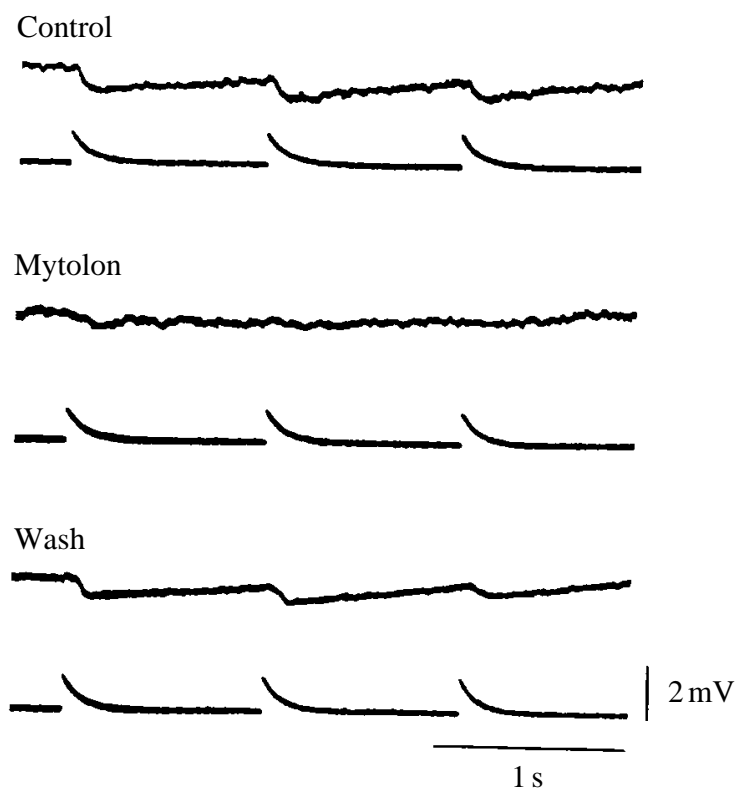

Fig. 8. Mytolon (benzoquinonium) $\left(3 \times 10^{-7} \mathrm{moll}^{-1}\right)$ blocked inhibitory junctional potentials (IJPs) elicited in the ventricle by stimulation of the intra-atrial cardiac nerve, as indicated by stimulus artifacts on the bottom traces in this and subsequent figures.

observed in M. mercenaria myocardium (data not shown). Similarly, hexamethonium did not antagonize the inverted IJPs (data not shown), although the drug is known to block $\mathrm{Na}^{+}-$ mediated ACh-induced depolarizing potentials in molluscan neurons (Gerschenfeld, 1973), M. mercenaria heart (Elliott, 1980) and gastropod hearts (Kuwasawa et al. 1987). IJPs were recorded from atrial, ventricular (Figs 5A, 6-8, 9B) and AV valve (Figs 5B, 9A, 10, 11) muscle cells, indicating that cholinergic nerve terminals are widely spread over all regions 
A
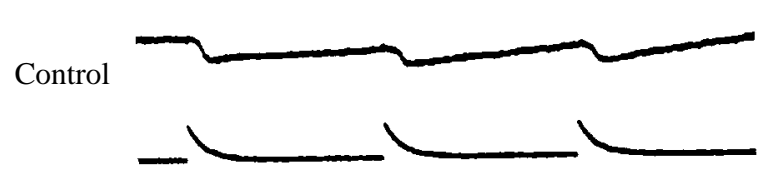

dTC
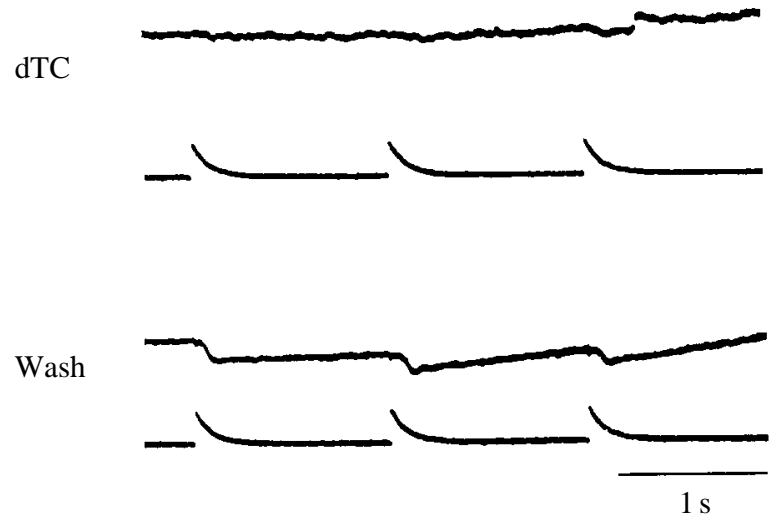

B
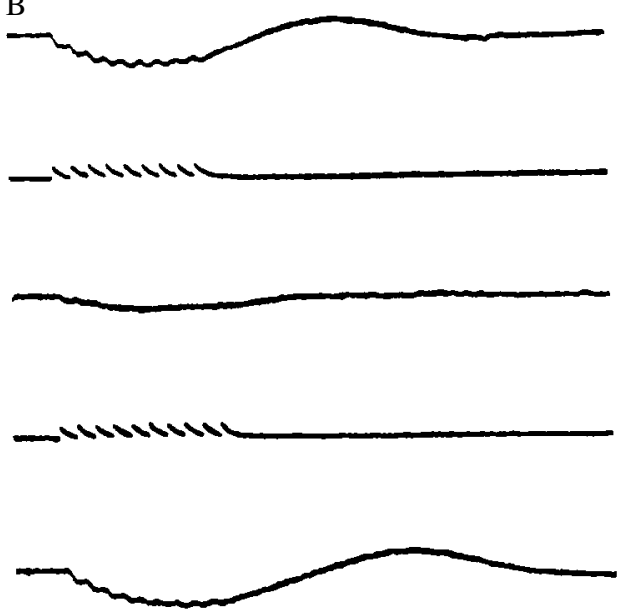

$2 \mathrm{mV}$

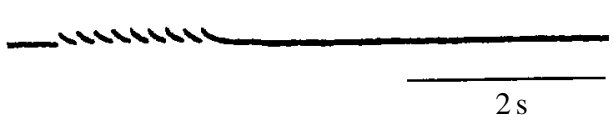

Fig. 9. (A) $d$-Tubocurarine (dTC) $\left(10^{-4} \mathrm{moll}^{-1}\right)$ blocked individual inhibitory junctional potentials (IJPs) in the atrio-ventricular (AV) valve. The top, middle and bottom traces were obtained before, during and after treatment with dTC. (B) dTC blocked summated IJPs induced in the ventricle by stimulation of the intra-atrial cardiac nerve. The rebound depolarization caused by hyperpolarization of summated IJPs at the cessation of the simulation (control) disappeared during application of the drug.

of the heart in M. mercenaria. This mode of inhibitory innervation differs from that found in the heart of the opisthobranch gastropod D. auricularia (Kuwasawa, 1979) where the ventricle does not appear to be innervated by

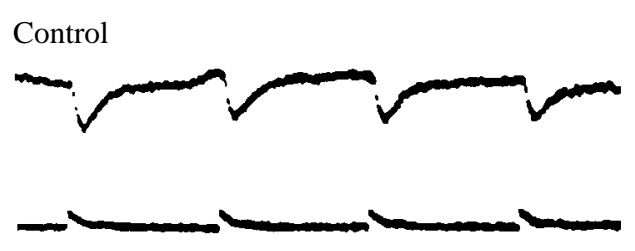

Low $\left[\mathrm{Cl}^{-}\right]$

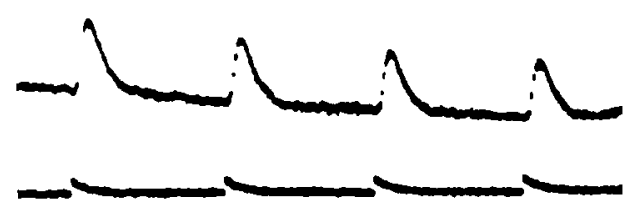

Wash

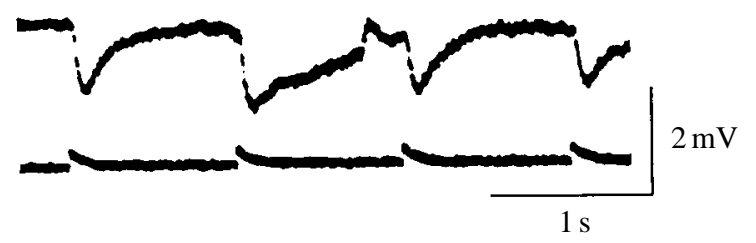

inhibitory nerves, but is somewhat similar to that seen in the prosobranch gastropod Busycon canaliculatum (Hill and Kuwasawa, 1990) where the ventricle is innervated by inhibitory nerves.

\section{Discussion}

\section{Origin of the cardiac nerve}

A paired nerve entering at the posterior end of the junction of the efferent branchial vessel, atrium and pericardium is probably the only route of innervation of the heart from the central nervous system. No nerve was found running along the anterior and posterior aortae in the pericardium, which are the only other possible pathways reaching the heart from outside the pericardium.

The central origins of the axons in the cardiac nerve were examined by stimulating the nerves arising from the visceral ganglion and from the cerebro-visceral connective. Stimulation of the nerves arising from the visceral ganglion produced both excitatory and inhibitory cardiac responses. When stimuli were applied to the connective, after cutting it at any site between the root of the cardiac nerve and the visceral ganglion or the cerebral ganglion, excitatory and inhibitory responses could

Fig. 10. Control hyperpolarizing inhibitory junctional potentials (IJPs) in the atrio-ventricular (AV) valve were inverted into depolarizing potentials in $\mathrm{Cl}^{-}$-deficient ASW (low $\left[\mathrm{Cl}^{-}\right]$), and the inverted potentials then recovered in artificial sea water (ASW) (wash). Resting membrane potentials were $-46 \mathrm{mV}$ in ASW and $-43 \mathrm{mV}$ in $\mathrm{Cl}^{-}$-deficient $\mathrm{ASW}$. 


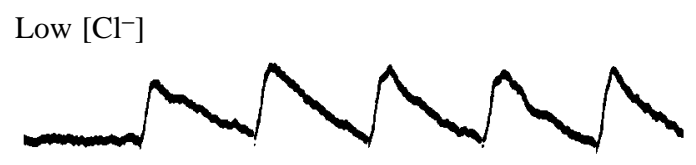

Low $\left[\mathrm{Cl}^{-}\right]+\mathrm{dTC}$
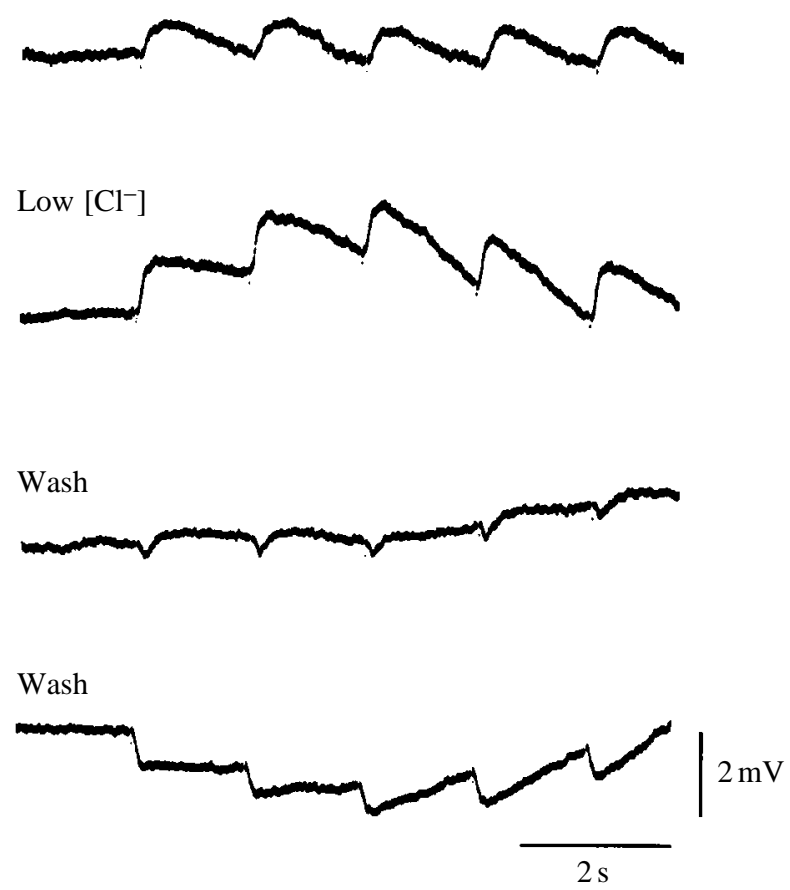

Fig. 11. Depolarizing inhibitory junctional potentials (IJPs) inverted during perfusion with $\mathrm{Cl}^{-}$-deficient artificial sea water (ASW) (low $\left[\mathrm{Cl}^{-}\right]$) were partially blocked $3 \mathrm{~min}$ from the onset of perfusion with $d$-tubocurarine (dTC) $\left(10^{-4} \mathrm{moll}^{-1}\right)$ in ASW (low $\left[\mathrm{Cl}^{-}\right]+\mathrm{dTC}$ ). Depolarizing IJPs recovered in $\mathrm{Cl}^{-}$-deficient ASW (low $\left[\mathrm{Cl}^{-}\right]$). Hyperpolarizing IJPs began to appear during washing with normal ASW (second trace from the bottom) and recovered with continued washing (bottom trace).

only be elicited by stimulation on the side towards the visceral ganglion of a stump posterior to the root of the cardiac nerve. These results indicate that cardiac nerve axons originate from neuron cell bodies located in the visceral ganglion, i.e. the cardiac nerve may arise from the visceral ganglion and run within the cerebro-visceral connective.

\section{Excitatory neuromuscular transmission in the myocardium}

Myocardial EJPs have been recorded in the prosobranch gastropod B. canaliculatum (Kuwasawa and Hill, 1973) and in the opisthobranch gastropods D. auricularia and Aplysia kurodai (Kuwasawa, 1967; Kuwasawa and Matsui, 1970), A. californica (Mayeri et al. 1974) and P. novaezealandiae (Kuwasawa et al. 1987). Hill and Kuwasawa (1990) showed that EJPs also mediate neurally induced cardiac excitation in the cephalopod Octopus hummelincki. In the present study, EJPs have been recorded from the myocardium of another major class of the Mollusca, the Bivalvia. This suggests that there may be a common neural excitatory control of the heart in molluscs mediated by EJPs. Serotonin has been shown to excite the heart in a variety of molluscan species (Greenberg, 1965; Hill and Welsh, 1966; Jones, 1983; Hill, 1974a), although it is cardioinhibitory in others (reviewed by Irisawa, 1978). The excitatory effects of serotonin are mediated by cyclic AMP in A. californica (Koester et al. 1979). In M. mercenaria, the ionic mechanisms controlling the excitation of the heart by serotonin have been investigated by Devlin (1992). In the current work, we recorded EJPs from myocardial cells of all the regions of the M. mercenaria heart; we tested these and showed that they were effectively blocked by methysergide.

Serotonin-like immunoreactive processes have been demonstrated in the hearts of the placophoran Liolophura japonica (Matsumura and Kuwasawa, 1988), the gastropods Aplysia californica (Goldstein et al. 1984; Ono et al. 1992) and P. novaezealandiae (Takeda and Kuwasawa, 1989), and in the bivalve Mercenaria stimpsoni (Kuwasawa et al. 1990). In A. californica, Ono et al. (1992) showed the presence of immunoreactive neural processes and detected significant amounts of serotonin in the heart using a radioenzymatic assay. Serotonin-like immunoreactivity in processes with varicosities was observed in all regions of the M. mercenaria heart, even the bulbus arteriosus, in the present study, suggesting that serotonin is a mediator for the EJPs in this tissue. However, in M. stimpsoni, a species closely related to M. mercenaria, the neural processes of the heart showed immunoreactivity to FMRFamide-related peptides (Kuwasawa et al. 1987), and FMRFamide has been shown to excite the heart of $M$. stimpsoni (Kuwasawa et al. 1992) and other bivalve species (Price et al. 1987; Hill and Kuwasawa, 1990). It is thus possible that EJPs may not be mediated by serotonin alone but that peptides may be cotransmitters. In fact, there may be a variety of cotransmitters (Gersch and Deuse, 1960). It is also possible that slow modulatory control may be provided by the release of neuropeptides since immunocytochemistry using anti-FMRFamide or anti-catch-relaxing peptide (CARP) antisera (a gift from Dr Y. Muneoka) revealed that, in the bivalve $M$. stimpsoni, the heart is innervated by peptidergic nerves containing FMRFamide and CARP. FMRFamide enhances heartbeat in M. stimpsoni and may thus be released by excitatory nerves while CARP slows the heartbeat and may, therefore, be secreted by inhibitory nerves (Kuwasawa et al. 1992).

\section{Inhibitory neuromuscular transmission in the myocardium}

In several species, ACh causes cardiac arrest associated with depolarization of the ventricular myocardium (Hill, 1974a,b; Kuwasawa, 1979) and hyperpolarization of the myocardium of the AV valve (Kuwasawa, 1979). The former was blocked by hexamethonium and the latter by dTC (Kuwasawa et al. 1987; Hill and Kuwasawa, 1990).

IJPs in the myocardium have been shown in Gastropoda (Kuwasawa, 1967, 1979; Kuwasawa and Hill, 1972; 
Kuwasawa et al. 1987) and Cephalopoda (Hill and Kuwasawa, 1990), and in the present paper we report that myocardial IJPs are induced one-to-one in response to stimulus pulses applied to the cardiac nerve in the bivalve species $M$. mercenaria. The IJPs were effectively blocked by dTC and Mytolon at concentrations similar to those used for blocking ACh effects on the hearts of bivalve species (Greenberg, 1965; Elliott, 1979, 1980). These results may indicate that ACh is a neurotransmitter of the inhibitory cardiac nerve in these bivalve molluscs. Kuwasawa et al. (1987) showed that, in gastropod hearts, both IJPs and potentials in response to electrophoretic application of ACh had the same pharmacological characteristics in that they were blocked by dTC and Mytolon but not by methylxylocholine.

In the present study, IJPs were normally hyperpolarizing and approximately $5 \mathrm{mV}$ in amplitude, but these were inverted into depolarizing IJPs of more than $5 \mathrm{mV}$ in amplitude in $\mathrm{Cl}^{-}$deficient ASW, although resting membrane potential remained almost the same. Both the hyperpolarizing and depolarizing IJPs were blocked by dTC (Fig. 9). These results suggest that IJPs were $\mathrm{Cl}^{-}$-mediated since $\mathrm{Cl}^{-}$-mediated $\mathrm{ACh}$ potentials are blocked by dTC in molluscan neurons (Gerschenfeld, 1973) in M. mercenaria heart (Elliott, 1980) and in a gastropod heart (Kuwasawa et al. 1987). Elliott (1980) showed that, in $M$. mercenaria myocardium, fast depolarizing potentials evoked by ionophoretic application of $\mathrm{ACh}$ were $\mathrm{Cl}^{-}$-dependent and blocked by dTC. She also showed that slow hyperpolarizing potentials were $\mathrm{K}^{+}$-dependent and were blocked by methylxylocholine but not by dTC. IJPs recorded from the myocardium of $M$. mercenaria are $\mathrm{Cl}^{-}$-dependent and not blocked by methylxylocholine and hexamethonium, but are blocked by dTC. If IJPs are cholinergic and neurally evoked at neuromuscular junctions, they might involve different $\mathrm{ACh}$ receptors from those involved in the fast depolarizing $\mathrm{ACh}$ potentials evoked by ionophoretic application of $\mathrm{ACh}$ to extrajunctional sites. However, the characteristics of IJPs and ACh potentials are quite similar except for the direction of the potentials, e.g. both are $\mathrm{Cl}^{-}$-dependent, dTC-sensitive and methlxylocholine- and hexamethonium-insensitive. $\mathrm{Na}^{+}-$ dependent ACh potentials were effectively blocked by hexamethonium in molluscan neurons (Gerschenfeld, 1973), M. mercenaria heart (Elliott, 1980) and a gastropod heart (Kuwasawa et al. 1987). We find that the dTC-sensitive $\mathrm{Cl}^{-}$dependent IJPs are inverted, from hyperpolarizing to depolarizing, when the $\mathrm{Cl}^{-}$equilibrium potential is shifted (Figs 10, 11). Previously, Elliott (1980) showed that ACh application, by ionophoresis through a micropipette, evoked tubocurarine-sensitive $\mathrm{Cl}^{-}$-dependent depolarizing potentials. Similarly, Kuwasawa et al. (1987) showed that ionophoresis of $\mathrm{ACh}$ onto gastropod myocardium evoked $\mathrm{Cl}^{-}$-dependent depolarizing potentials, which were inverted when the $\mathrm{Cl}^{-}$ equilibrium potential was shifted. Possibly, the dTC-sensitive $\mathrm{Cl}^{-}$-dependent IJPs and ACh-evoked depolarizing potentials are related, since the IPSPs can be inverted. (ACh-evoked hyperpolarizing potentials are another matter, on which we have little evidence as yet.)
We may conclude that the heart of $M$. mercenaria is controlled by excitatory and inhibitory nerves from the visceral ganglion, which evoke discrete junctional potentials.

\section{Significance of myocardial excitation and inhibition for cardiovascular physiology}

In the present paper, we have provided evidence for cardiac control by EJPs and IJPs in M. mercenaria. These are unitary events which provide the basis for overall control of cardiac output in M. mercenaria and other molluscs. Koester et al. (1979) have reviewed many environmental demands for modulation of heart rate in bivalves and gastropods, which include emersion, hypoxia, hypercapnia, feeding and nutritional level, temperature and tactile or chemical stimuli. Certain aspects of overall cardiovascular control are best understood in the sea hare Aplysia californica and the pond snail Lymnaea stagnalis, where integrated neural and neurohumoral control is quite complex (reviewed by Skelton et al. 1992a). In A. californica, for example, the role of cardiovascular control neurons in adaptation of the heart to respiratory pumping is well understood (reviewed by Skelton et al. 1992b). The heart is relaxed by cholinergic inhibitor motoneurones, while contraction of the gill drives blood to the heart. During feeding, heart rate is increased by a heart excitor motoneuron which synthesizes serotonin (5-HT) and a peptide with a parallel excitatory action, probably mediated by cyclic AMP. The nerve networks that control cardioexcitatory and cardioinhibitory neurons also function in related activities including feeding and respiration (reviewed by Skelton $e t$ al. 1992b).

Identified central motoneurons of $A$. californica drive serotonergic cardiac excitation (reviewed by Koester and Koch, 1987). For instance, identified motoneuron $\mathrm{RB}_{\mathrm{HE}}$ causes a relatively long-lasting increase in heart rate which is blocked by a serotonin antagonist, while identified motoneuron $\mathrm{LD} H \mathrm{HE}$ excites for the duration of one beat. The multi-modal motoneuron $\mathrm{L}_{7}$ drives fast EJPs in A. californica atrium, which can initiate a beat in the quiescent heart, and the twin central motoneurons $\mathrm{LD}_{\mathrm{HI}}$ drive inhibition of the heart of $A$. californica which is blocked by a cholinergic antagonist (Koester and Koch, 1987).

Central motoneurons are relatively inaccessible in the prosobranch gastropod Busycon canaliculatum, but it has provided rugged whole-heart preparations giving a comprehensive overview of the function of EJPs and IJPs. Ventricular rhythmicity in B. canaliculatum is regulated by the interaction of IJPs and EJPs (reviewed by Kuwasawa and Hill, 1973). Summating compound IJPs inhibit the heart by hyperpolarization, while summating compound EJPs excite the heart by depolarization. Thus, cardiac activity may be controlled by summating (but not facilitating) EJPs and IJPs. Afferent activity in the cardiac nerve of $B$. canaliculatum shows a burst of activity during each spontaneous contraction. In response to stretches, there are slowly adapting 'on' volleys for the duration of the stretch and brief 'off' volleys. Together, the observed efferent and afferent activity provides the basis 
for reflex control of the heart. In fact, the efferent activity appears in intracardiac branches of the cardiac nerve in response to afferent activity induced by stretching the ventricle with a Levin-Wyman ergometer (Kuwasawa et al. 1975). If one considers the role of IJPs and EJPs in overall control of the heart in B. canaliculatum, it appears that heartbeats or distension of the heart set up afferent traffic in the cardiac nerve, which can be traced as far as the visceral ganglion. The major part of this traffic originates in neuropil near the aorta, but the visceral ganglion exerts a marked inhibitory tone on efferent traffic. The predominant effect of stimulation of the cardiac nerve is to elicit IJPs, so it appears that, as each contraction of the heart progresses, afferent traffic increases and arouses reflex inhibition of the heart.

Our work on neuromuscular transmission in the myocardium of $M$. mercenaria does indicate cholinergic IJPs and serotonergic EJPs, although other transmitters have not been excluded. It is natural to think of cholinergic IJPs as inhibitory and serotonergic EJPs as excitatory in the physiological control of the whole heart, but the situation is, in fact, more complex. In bivalves, as well as snails, cephalopods and Aplysia californica, both end-diastolic volume and heart rate increase when metabolic or environmental demands call for increased cardiac output (reviewed by Armstrong and Smith, 1992).

Acetylcholine and 5-HT have long been thought to be typical of neurohumors involved in cardiac regulation in molluscs, although their roles in excitation and inhibition may be reversed from species to species (reviewed by Irisawa, 1978). For the purposes of this discussion, we will direct attention to 'excitation' by 5 -HT and 'inhibition' by $\mathrm{ACh}$. At the membrane level, 5-HT is involved in excitation by evoked EJPs (the present paper and reviews, e.g. Kuwasawa and Hill, 1973). However, it has long been known that 5-HT may activate adenyl cyclase in molluscan hearts (reviewed by Cottrell and Osborne, 1969). 'Second messengers' do not appear to be elicited by ACh, so we can simply say that, at the membrane level, ACh is involved in inhibition by evoked IJPs (the present paper and reviews, e.g. Kuwasawa and Hill, 1973; Hill and Kuwasawa, 1990). However, the effects of chemical transmitter agents on the entire working heart are rather more complex than simple excitation and inhibition. The actions of 5-HT, ACh and FMRFamide on the entire isolated working heart of $B$. canaliculatum (Smith and Hill, 1986, 1987) have been reviewed by Smith $(1985 a, 1987,1990)$. These actions link neural excitation and inhibition to heart function and may be interpreted in terms of cardiovascular function during the overall pattern of activity in the living intact mollusc (Jones, 1970, 1983, 1988). Jones (1983) has reviewed the range of cardioactive substances that may control the molluscan heart in situ, including the probable cardioregulatory neurotransmitters ACh, 5-HT and FMRFamide. We have shown that $\mathrm{ACh}$ acts as an inhibitory neurotransmitter in the heart of M. mercenaria. However, studies of the intact working heart of $B$. canaliculatum show that this inhibitory neurotransmitter may interact with excitatory neurotransmitters to increase stroke volume (Smith and Hill, 1986, 1987). This was shown using an isolated heart cannulated at the branchial vein and aorta. If the preparation is supplied with saline containing a solution of $\mathrm{ACh}$, less perfusate is ejected at a lower pressure, so the temptation is to say, 'Ah-hah! Inhibition!'. This results from reduced stroke volume and lowered heart rate, plus reduced amplitude and increased duration of the aortic pressure pulse. However, since $\mathrm{ACh}$ reduces myocardial tone, there is an increase in both end-diastolic and end-systolic volume. If taken together with the simultaneous action ('excitatory') of 5-HT or FMRFamide, this increase in end-diastolic volume leads to an increase in stroke volume. 5-HT is an excitatory neurotransmitter in the heart of M. mercenaria and in many other molluscan myocardia (Painter and Greenberg, 1982). When the isolated working intact heart of B. canaliculatum is perfused with solutions containing 5-HT alone, there is no effect on one physiologically important value, stroke volume, but there is a very marked increase in aortic pulse pressure and a shortening of the ejection time. If one considers the concerted action of ACh and 5-HT, it appears that output of increased stroke volume, even against increased total peripheral resistance, is the result of a synergistic action of ACh and 5-HT (Smith, 1987). To summarize, Smith and Hill (1986, 1987) found that, at the whole heart level, the 'excitatory' neurotransmitter (5-HT) increases aortic pulse pressure by as much as $250 \%$ while reducing output pulse duration by as much as $50 \%$. The same stroke volume is thus ejected faster and at a higher pressure. In contrast, the 'inhibitory' neurotransmitter (ACh) has the effect of increasing end-diastolic volume, while lengthening the pressure pulse. Since cholinergic and aminergic innervations are unlikely to act in isolation, Smith and Hill (1987) pointed out that it is too simplistic to characterize the innervation as either excitatory or inhibitory. Instead, they would work together to regulate cardiac output, the aminergic innervation tending towards directing output of an increased end-diastolic volume, supported by the cholinergic innervation (FMRFamide acts rather like 5-HT). Jones (1988) has shown that in vivo cardiac pressures in B. canaliculatum are in the range used with the whole working heart in vitro by Smith and Hill (1986, 1987). In the present paper, we have examined postsynaptic mechanisms in the heart of $M$. mercenaria, where heterometric and homeometric regulation of the whole heart (Smith, 1985b) are quite similar to regulation in B. canaliculatum. We may expect that the roles of the neurotransmitters in the regulation of the heart in vivo are not dissimilar.

We thank Dr S. Matsumura for his assistance throughout the course of the immunocytochemistry in this study. This study was partly supported by a Grant-in-Aid for International Scientific Joint Research no. 02044122 and Scientific Research (B) no. 04454028 from the Ministry of Education, Science and Culture of Japan. 


\section{References}

Armstrong, J. And Smith, P. J. S. (1992). Dynamic responses of cardiac output. In Phylogenetic Models in Functional Coupling of the CNS and the Cardiovascular System (ed. R. B. Hill and K. Kuwasawa). Comp. Physiol. 11, 15-21. Basel: Karger.

Berod, A., Hartman, B. K., Keller, A., John, T. H. and Pujol, J. F. (1982). A new double labeling technique using tyrosine hydroxylase and dopamine- $\beta$-hydroxylase immunochemistry: Evidence for dopaminergic cells lying in the pons of the beef brain. Brain Res. 240, 235-243.

Berod, A., Hartman, B. K. AND Pujol, J. F. (1981). Importance of fixation in immunohistochemistry: Use of formaldehyde solutions at variable $\mathrm{pH}$ for the localization of tyrosine hydroxylase. $J$. Histochem. Cytochem. 29, 844-850.

Cottrell, G. A. AND Osborne, N. N. (1969). Localization and mode of action of cardioexcitatory agents in molluscan hearts. Experientia (Suppl.) 15, 220-231.

Devlin, C. L. (1993a). An analysis of control of the ventricle of a mollusc Mercenaria mercenaria. I. The ionic basis of autorhythmicity. J. exp. Biol. 179, 47-61.

Devlin, C. L. (1993b). An analysis of control of the ventricle of the clam Mercenaria mercenaria. II. Ionic mechanisms involved in excitation by 5-hydroxytryptamine. J. exp. Biol. 179, 63-75.

Devlin, C. L. (1992). Electrophysiological and pharmacological properties of excitation in the ventricle of the mollusc, Mercenaria mercenaria. In Phylogenetic Models in Functional Coupling of the CNS and the Cardiovascular System (ed. R. B. Hill and K. Kuwasawa). Comp. Physiol. 11, 166-181. Basel: Karger.

ElliotT, E. J. (1979). Cholinergic response in the heart of the clam Mercenaria mercenaria: Activation by a Conus californicus venom component. J. comp. Physiol. 129, 61-66.

ElliotT, E. J. (1980). Three types of acetylcholine response in bivalve heart muscle cells. J. Physiol., Lond. 300, 283-302.

GERSCH, M. AND DEUSE, R. (1960). Über herzaktive faktoren aus den Nervensystem von Aplysia. Zool. Jahrb. Abt. Allgem. Zool. u. Physiol. Tiere 68, 519-534.

GersChENFELD, H. M. (1973). Chemical transmission in invertebrate central nervous systems and neuromuscular junctions. Physiol. Rev. 53, $1-119$.

Goldstein, R., Kistler, H. B., JR, Steinbush, H. W. M. And SCHWARTZ, J. H. (1984). Distribution of serotoninimmunoreactivity in juvenile Aplysia. Neurosci. 11, 535-547.

GREENBERG, M. J. (1960). Structure-activity relationship of tryptamine analogues on the heart of Venus mercenaria. Br. J. Pharmac. 15, 365-375.

GREENBERG, M. J. (1965). A compendium of responses of bivalve hearts to acetylcholine. Comp. Biochem. Physiol. 14, 513-539.

HILL, R. B. (1974a). Effects of 5-hydroxytryptamine on action potentials and on contractile force in the ventricle of Dolabella auricularia. J. exp. Biol. 61, 529-539.

HILL, R. B. (1974b). Effects of acetylcholine on resting and action potentials and contractile force in the ventricle of Dolabella auricularia. J. exp. Biol. 61, 629-637.

HiLl, R. B. AND Kuwasawa, K. (1990). Neuromuscular transmission in molluscan hearts. Zool. Sci. 7, 999-1011.

Hill, R. B. AND Welsh, J. H. (1966). Heart, circulation and blood cells. In Physiology of Mollusca, vol. 2 (ed. K. M. Wilbur and C. M. Yonge), pp. 125-174. New York: Academic Press.

IRISAWA, H. (1978). Comparative physiology of the cardiac pacemaker mechanism. Physiol. Rev. 58, 461-498.

Irisawa, H., Wilkens, L. A. AND GreenberG, M. J. (1973). Increase in membrane conductance by 5-hydroxytryptamine and acetylcholine on the hearts of Modiolus demissus demissus and Mytilus edulis (Mytilidae, Bivalvia). Comp. Biochem. Physiol. 45A, 653-666.

Jones, H. D. (1970). Hydrostatic pressure within the heart and pericardium of Patella vulgata L. Comp. Biochem. Physiol. 34, 263-272.

JoNES, H. D. (1983). The circulatory systems of gastropods and bivalves. In The Mollusca, vol. 5 (ed. K. M. Wilbur), pp. 189-238. New York: Academic Press.

JONES, H. D. (1988). In vivo cardiac pressure and heart rate and heart mass of Busycon canaliculatum (L.). J. exp. Biol. 140, 257-271.

KEHOE, J. (1972a). Ionic mechanisms of a two-component cholinergic inhibition in Aplysia neurones. J. Physiol., Lond. 225, 84-114.

KeHOE, J. (1972b). Three acetylcholine receptors in Aplysia neurones. J. Physiol., Lond. 225, 115-146.

KLING, G. (1986). Histochemical localization of cholinesterases and monoamines in the central heart of Sepia officinalis L. (Cephalopoda). Histochemistry 85, 241-250.

Koester, J., Dieringer, N. And Mandelbaum, D. E. (1979). Cellular neuronal control of molluscan heart. Am. Zool. 19, 103-116.

KoEster, J. AND Koch, U. T. (1987). Neural control of the circulatory system of Aplysia. Experientia 43, 972-980.

Kurokawa, M., Kuwasawa, K., Otokawa, M., Yamada, C. And KoBAYASHI, H. (1989). Aminergic cellular organization in the gills of Aplysia species. J. Neurobiol. 2, 731-745.

KuwasawA, K. (1967). Transmission of impulse from the cardiac nerve to the heart in some molluscs (Aplysia and Dolabella). Sci. Rep. Tokyo Kyoiku Daigaku Sec. B 13, 111-128.

Kuwasawa, K. (1979). Effects of ACh and IJPs on the AV valve and the ventricle of Dolabella auricularia. Am. Zool. 19, 129-143.

Kuwasawa, K. AND HiLl, R. B. (1972). Interaction of inhibitory and excitatory junctional potentials in control of the myogenic myocardium of the ventricle of Busycon canaliculatum. Experientia 28, 800-801.

Kuwasawa, K. AND HiLl, R. B. (1973). Regulation of ventricular rhythmicity in the hearts of prosobranch gastropods. In Neurobiology of Invertebrates: Mechanisms of Rhythm Regulation (ed. J. Salánki), pp. 143-165. Budapest: Akadémiai Kiadó.

Kuwasawa, K. AND Matsui, K. (1970). Postjunctional potentials and cardiac acceleration in a mollusc (Dolabella auricularia). Experientia 26, 1100-1101.

Kuwasawa, K., Matsumura, S. and Kurokawa, M. (1990). Serotonergic innervation of the heart and arteries in some molluscan species. Zool. Sci. 7, 1036.

Kuwasawa, K., Matsumura, S. and Kurokawa, M. (1992). Immunocytochemical and physiological studies of FMRFamide, catch-relaxing peptide and GWamide in the heart of molluscs. In Phylogenetic Models in Functional Coupling of the CNS and the Cardiovascular System (ed. R. B. Hill and K. Kuwasawa). Comp. Physiol. 11, 220-230. Basel: Karger.

Kuwasawa, K., Neal, H. and Hill, R. B. (1975). Afferent pathways in the innervation of the ventricle of a prosobranch gastropod Busycon canaliculatum L. J. comp. Physiol. 96, 73-83.

Kuwasawa, K. AND YaZAwa, T. (1981). Effects of tubocurarine on excitatory and inhibitory junctional potentials in the heart of Dolabella auricularia. In Neurotransmitters in Invertebrates (ed. K. S.-Rózsa), pp. 113-132. Adv. Physiol. Sci. Pergamon Press, Akadémiai Kiadó, Budapest, vol. 22. 


\section{Bivalve cardiac postjunctional potentials 2135}

Kuwasawa, K., Yazawa, T. and KuRoKawa, M. (1987). Inhibitory neural control of the myocardium in opisthobranch molluscs. Experientia 4, 986-990.

Liebeswar, G., Goldman, J. E., Koester, J. and Mayeri, E. (1975). Neural control of circulation in Aplysia III. J. Neurophysiol. 38, 767-779.

Loveland, R. E. (1963a). Some aspects of cardio-regulation in Mercenaria mercenaria. $\mathrm{PhD}$ thesis, Harvard University.

Loveland, R. E. (1963b). 5-Hydroxytryptamine, the probable mediator of excitation in the heart of Mercenaria (Venus) mercenaria. Comp. Biochem. Physiol. 9, 95-104.

Matsumura, S. AND Kuwasawa, K. (1988). Histochemical analysis of aminergic nervous systems in the pericardium and the heart of Liolophura japonica. Zool. Sci. 5, 1215.

Mayeri, E., Koester, J., Kupfermann, I., Liebeswar, G. AND KANDEL, E. R. (1974). Neural control of circulation in Aplysia. I. Motoneurons. J. Neurophysiol. 37, 458-475.

Ono, J. K., Hampton, J. D. R. AND Koch, R. A. (1992). Immunohistochemical localization and radioenzymatic measurements of serotonin (5-hydroxytryptamine) in hearts of Aplysia and several bivalve mollusks. Cell. Tissue Res. 269, 421-430.

Painter, S. D. And Greenberg, M. J. (1982). A survey of the responses of bivalve hearts to the molluscan neuropeptide FMRFamide and to 5-hydroxytryptamine. Biol. Bull. mar. biol. Lab., Woods Hole 162, 311-332.

Price, D. A., Davies, N. W., Doble, K. E. and Greenberg, M. J. (1987). The variety of distribution of the FMRFamide-related peptides in molluscs. Zool. Sci. 4, 395-401.

SHigeto, N. (1970). Excitatory and inhibitory actions of acetylcholine on hearts of oyster and mussel. Am. J. Physiol. 218, 1773-1779.

Skelton, M., Alevizos, A. And Koester, J. (1992a). Neural and neurohumoral control of the cardiovascular system of Aplysia. In Phylogenetic Models in Functional Coupling of the CNS and the
Cardiovascular System (ed. R. B. Hill and K. Kuwasawa). Comp. Physiol. 11, 182-184. Basel: Karger.

Skelton, M., Alevizos, A. And Koester, J. (1992b). Control of the cardiovascular system of Aplysia by identified neurons. Experientia 48, 809-817.

SMith, P. J. S. (1985a). Molluscan circulation: haemodynamics and the heart. In Circulation, Respiration and Metabolism (ed. R. Gilles), pp. 344-355. Berlin: Springer-Verlag.

SMITH, P. J. S. (1985b). Cardiac performance in response to loading pressures in Busycon canaliculatum (Gastropoda) and Mercenaria mercenaria (Bivalvia). J. exp. Biol. 119, 301-320.

SMITH, P. J. S. (1987). Cardiac output in the Mollusca: Scope and regulation. Experientia 43, 956-965.

SMITH, P. J. S. (1990). Integrated cardiovascular control in the Mollusca. Physiol. Zool. 63, 12-34.

SMith, P. J. S. AND HiLl, R. B. (1986). Cardiac performance in response to loading pressures and perfusion with 5hydroxytryptamine in the isolated heart of Busycon canaliculatum. J. exp. Biol. 123, 243-253.

SMITH, P. J. S. AND HiLl, R. B. (1987). Modulation of output from an isolated gastropod heart: effects of acetylcholine and FMRFamide. J. exp. Biol. 127, 105-120.

TAKEDA, E. AND KuWASAWA, K. (1989). Distribution of serotonergic neurons in the whole central nervous system of a Gastropoda mollusc, Pleurobranchaea novaezealandiae. Zool. Sci. 6, 1094.

TAUC, L. AND Gerschenfeld, H. M. (1962). A cholinergic mechanism of inhibitory synaptic transmission in a molluscan nervous system. J. Neurophysiol. 25, 236-262.

Welsh, J. H. AND TAUB, R. (1948). The action of choline and related compounds on the heart of Venus mercenaria. Biol. Bull. mar. biol. Lab., Woods Hole 95, 346-353.

Welsh, J. H. AND TAUB, R. (1953). The action of acetylcholine antagonists on the heart of Venus mercenaria. Br. J. Pharmac. 8, 327-333. 